Check for updates

Cite this: RSC Adv., 2017, 7, 48723

Received 23rd August 2017

Accepted 29th September 2017

DOI: 10.1039/c7ra09351a

rsc.li/rsc-advances

\section{First graphene oxide promoted metal-free nitrene insertion into olefins in water: towards facile synthesis of activated aziridines $\uparrow$}

\author{
Prashant Shukla, ${ }^{a}$ Suhasini Mahata, ${ }^{\text {b }}$ Anjumala Sahu, ${ }^{\text {b }}$ Manorama Singh, iD b \\ Vijai K. Rai iD b and Ankita Rai iD *a
}

\begin{abstract}
A facile metal-free graphene oxide (GO)-catalyzed synthesis of tosylaziridines using $\mathrm{Phl}=\mathrm{NT}$ s as the nitrene source is reported. The reaction involves nitrene insertion into a variety of styrene/nitrostyrene derivatives in the presence of iodine at room temperature and in water. The envisaged process is highly green, operationally simple, it employs metal-free catalysis and it affords excellent yields (85-92\%) and high diastereoselectivity (95-98\%) of the Z-isomer of the product. The catalyst used could be recycled for further use in other reactions.
\end{abstract}

Aziridines have been synthetic targets as well as scaffolds since Gabriel's discovery in 1888. They represent an important structural motif in drugs and natural products (Fig. 1) and are highly useful as feedstock in organic synthesis to provide functionalized carbon chains due to the inherent strain in small ring heterocycles. ${ }^{1}$ In terms of synthetic transformations, the utility of aziridines arises from their selective ring-opening reactions using various nucleophiles, which often form the basis of more complex target syntheses. ${ }^{2,3}$ Owing to their chemical and biological interest, numerous methods are reported for their synthesis, ${ }^{4-14}$ including the aziridination of olefins, ${ }^{4-6}$ the addition of carbene and ylide to imines, ${ }^{7-9}$ and different cyclization protocols. ${ }^{10-14}$ However, the direct transfer of nitrogen atoms to alkenes has been the most practical and useful method for the synthesis of aziridines..$^{15}$ Although transition-metal catalyzed aziridination of alkenes has been well reported in the literature, metal-free aziridination using different nitrogen sources is still an attractive strategy from practical, economical and, of course, environmental points of view. ${ }^{16-20}$ The nitrene transfer reaction, ${ }^{21,22}$ and the use of iminoiodinanes ${ }^{23}$ as nitrene precursors and thus the efficient conditions for catalytic aziridination of olefins using iodine(III) oxidants are reported. ${ }^{24}$ Despite previous work, the development of more environmentally benign nitrene transfer reactions for the construction of diverse aziridines is still in great demand. Thus, inspired by these reports and in continuation of our interest in developing efficient and green catalytic routes ${ }^{25}$

${ }^{a}$ School of Physical Sciences, Jawaharlal Nehru University, New Delhi, 110027, India. E-mail: ankitarai@mail.jnu.ac.in; Tel: +91-11-26738808

${ }^{b}$ Department of Chemistry, School of Physical Sciences, Guru Ghasidas Vishwavidyalaya, Bilaspur (C.G.)-495009, India

$\dagger$ Electronic supplementary information (ESI) available: Characterization details are given. See DOI: 10.1039/c7ra09351a for bioactive molecules ${ }^{26}$ we decided to undertake the aziridination of olefins using $\mathrm{PhI}=\mathrm{NTs}$ as the nitrene source. ${ }^{27}$ Recently, we have reported the synthesis of functionalized graphene oxide, ${ }^{28}$ which could easily be dispersed in water. Keeping the use of water as a reaction medium in mind, we anticipated using the reported Fe-decorated GO as a catalyst for the present investigation. To our surprise, we were successful in isolating the target aziridine but the yield was not satisfactory. Then we turned our attention to employing a metal-free catalytic process and tried graphene oxide only as a catalyst in the presence of $\mathrm{PhI}=\mathrm{NTs}$ and $\mathrm{I}_{2}$ and the reaction was successful in terms of yield of pure product. Herein, we disclose a metal-free aziridination of styrenes as well as nitrostyrenes using an equimolar amount of $\mathrm{PhI}=\mathrm{NTs}$ in the presence of $\mathrm{I}_{2}$ using GO as the catalyst in an aqueous medium and at ambient reaction conditions (Scheme 1). To the best of our knowledge, the aziridination of olefins through graphene oxide-catalyzed nitrene insertion reactions under metal-free conditions using water as a solvent has not been reported so far.

In our preliminary experimentation, we first examined equimolar mixtures of styrene $1 \mathrm{a}$ and $\mathrm{PhI}=\mathrm{NTs} 2$ with $10 \mathrm{~mol} \%$ of $\mathrm{I}_{2}$ in water at room temperature (Table 1 , entry 1 ), but we did not isolate product $\mathbf{3 a}$ without the use of a catalyst, even upon

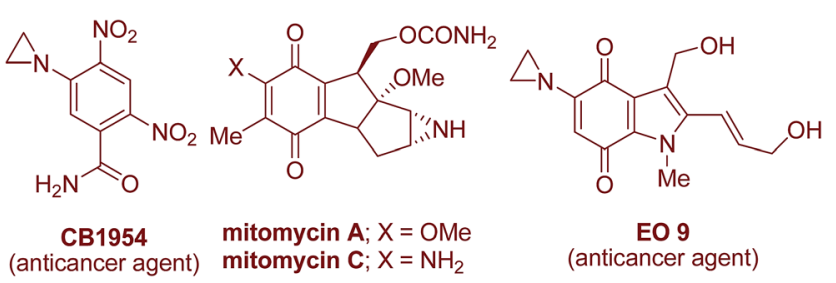

Fig. 1 Drugs and natural products containing aziridine. 


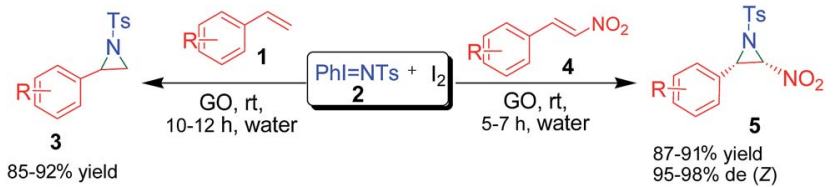

Scheme 1 Synthesis of the GO-catalyzed aziridination of olefins.

Table 1 Screening of catalysts and solvents for the aziridination of styrene $1 a^{a}$

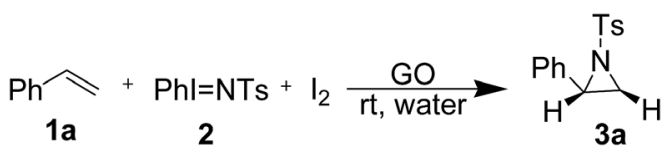

\begin{tabular}{llllll} 
Entry & Catalyst $(\mathrm{mg})$ & $\mathrm{I}_{2}(\mathrm{~mol} \%)$ & Solvent & Time $^{b}(\mathrm{~h})$ & Yield $^{c, d}(\%)$ \\
\hline 1 & - & 10 & Water & 12 & - \\
2 & - & 10 & MeOH & 12 & - \\
3 & - & 10 & MeCN & 12 & - \\
4 & - & 10 & THF & 12 & - \\
5 & - & 10 & $1,4-$ Dioxane & 12 & - \\
6 & Fe-GO (15) & 10 & $\mathrm{H}_{2} \mathrm{O}$ & 12 & 43 \\
7 & GO (15) & 10 & $\mathrm{H}_{2} \mathrm{O}$ & 10 & 92 \\
8 & rGO (15) & 10 & $\mathrm{H}_{2} \mathrm{O}$ & 12 & - \\
9 & Graphite & 10 & $\mathrm{H}_{2} \mathrm{O}$ & 12 & - \\
10 & GO (15) & 10 & $\mathrm{Benzene}$ & 10 & - \\
11 & GO (15) & 10 & DCM & 12 & 23 \\
12 & GO (15) & 10 & DMF & 10 & - \\
13 & GO (15) & 10 & THF & 10 & 29 \\
14 & GO (15) & 10 & $\mathrm{MeOH}^{2}$ & 10 & 53 \\
15 & GO (10) & 10 & $\mathrm{H}_{2} \mathrm{O}$ & 10 & 73 \\
16 & GO (20) & 10 & $\mathrm{H}_{2} \mathrm{O}$ & 10 & 92 \\
17 & GO (15) & 5 & $\mathrm{H}_{2} \mathrm{O}$ & 10 & - \\
18 & GO (15) & 10 & $\mathrm{H}_{2} \mathrm{O}$ & 10 & 92
\end{tabular}

${ }^{a}$ Reaction conditions: a mixture of $1 \mathrm{a}$ ( 1 equi.), 2 (1 equi.), $\mathrm{I}_{2}$ (15 mol\%) and $\mathrm{GO}(15 \mathrm{mg})$ in $5 \mathrm{~mL}$ of water was stirred at room temperature. ${ }^{b}$ The stirring time at room temperature. ${ }^{c}$ Yield of isolated and purified product. ${ }^{d}$ Characterized by spectral (IR, ${ }^{1} \mathrm{H}$ NMR, ${ }^{13} \mathrm{C}$ NMR and EIMS) data. ${ }^{e}$ The reaction was carried out in the dark.

changing the solvent system (MeOH, MeCN, THF and 1,4dioxane) (Table 1, entries 2-5). Next, the screening of the catalytic and solvent systems was undertaken, as given in Table 1. Initially, we used our recently reported catalyst,$^{28} \mathrm{Fe}-\mathrm{GO}(15 \mathrm{mg})$ using water as a solvent, and we successfully isolated the corresponding aziridine product $\mathbf{3 a}$ in moderate yield (Table 1, entry 6). Encouraged by the result, we tried several graphenebased materials as catalysts in the present synthetic protocol (Table 1, entries 6-9). However, GO was found to be the most effective among GO, rGO, graphite and Fe-GO, while rGO and graphite were ineffective for the conversion (Table 1, entries 8 and 9). The optimum catalyst loading for graphene oxide was found to be $15 \mathrm{mg}$. When the amount of catalyst decreased from $15 \mathrm{mg}$ to $10 \mathrm{mg}$, the yield of product $3 \mathrm{a}$ reduced (Table 1, entry 15) but the use of $20 \mathrm{mg}$ of the catalyst showed the same yield (Table 1, entry 16). Solvent screening for the synthesis of 3a was also undertaken using various solvents such as MeCN, DCM, 1,4-dioxane, THF, MeOH and water (Table 1, entries 7, 10-14). When the reaction was carried out in aprotic solvents such as MeCN, DCM, 1,4-dioxane and THF, it afforded the aziridine 3a in trace amounts (Table 1). However, when using polar protic solvents, the yield was improved (Table 1, entry 14) and therefore, water was found to be the best choice of solvent in the present optimization process.

The role of $\mathrm{I}_{2}$ was also investigated and a reaction of $1 \mathrm{a}$ and 2 and $\mathrm{GO}(15 \mathrm{mg})$ was performed in the absence of iodine, but no aziridine 3a was isolated (Table 1, entry 17 ) which is evidence that iodine plays a crucial role in the formation of aziridine rings. When the reaction was performed in the dark it afforded 3a in low yield, showing that the reaction involved a radical which was promoted by ambient room light in the laboratory (Table 1, entry 18).

After optimization of the reaction conditions, we next investigated the substrate scope of the present aziridination of styrene. The substituents on the benzene ring of styrene 1 did not show any specific effect over the product outcome as well as the conversion rate. Substrates with electron-donating and electron withdrawing substituents at the para-position were tolerated to afford the corresponding aziridine 3 in consistently good yields (Table 2). Substituents at the ortho or meta positions on the phenyl ring caused almost no change in reactivity (Table 2, entries 7 and 8). However, when using an aliphatic alkene, a moderate yield of the corresponding aziridine was obtained. The formation of product $\mathbf{3}$ was confirmed by spectral analysis. In the ${ }^{1} \mathrm{H}$ NMR spectra of 3a (Fig. S1; ESI $\dagger$ ), a double doublet at $\delta 3.78(J=7.0,4.5 \mathrm{~Hz})$ for $\mathrm{CH}$ indicates the presence of two vicinal $\mathrm{CH}_{2}$ protons, further confirmed by two doublets at $\delta 2.99$ $(J=7.0 \mathrm{~Hz})$ and $\delta 2.43(J=4.5 \mathrm{~Hz})$. Thus, the present optimized synthesis of stirring an equimolar mixture of styrene $\mathbf{1}$ and

Table 2 Substrate scope of styrene 1 in the present aziridination process $^{a}$

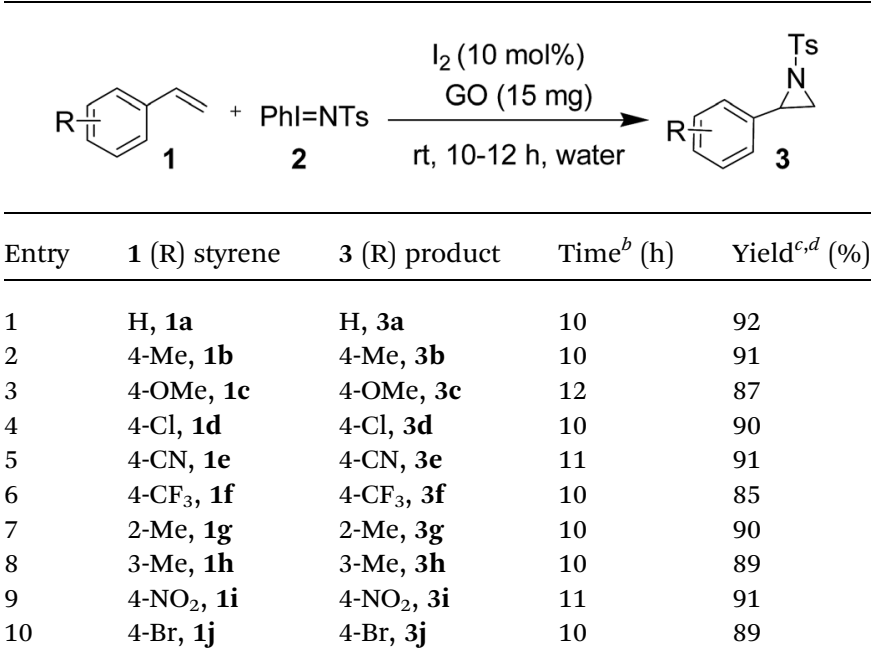

${ }^{a}$ Reaction conditions: a mixture of $1(0.75 \mathrm{mmol}), 2(0.75 \mathrm{mmol}), \mathrm{I}_{2}$ $(0.075 \mathrm{mmol})$ and $\mathrm{GO}(15 \mathrm{mg})$ dispersed in $5 \mathrm{~mL}$ of water was stirred at room temperature. ${ }^{b}$ The stirring time at room temperature. ${ }^{c}$ Yield of isolated and purified product. ${ }^{d}$ Characterized by spectral (IR, ${ }^{1} \mathrm{H}$ NMR, ${ }^{13} \mathrm{C}$ NMR and EIMS) data. 


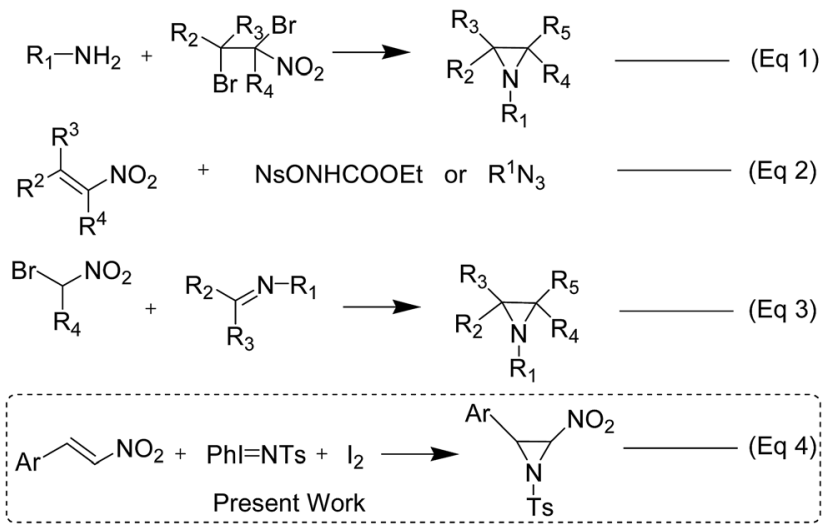

Scheme 2 Various synthetic routes for the synthesis of nitroaziridines.

$\mathrm{PhI}=$ NTs 2 , iodine $(10 \mathrm{~mol} \%)$ and GO $(15 \mathrm{mg})$ in water for $10-$ $12 \mathrm{~h}$ was successful and afforded tosylaziridine 3 in $85-92 \%$ yields (Table 2).

Although 2-nitroaziridines appear to be a scaffold for further transformation, very few reports are available on the synthesis of $C$-nitroaziridines ${ }^{12,30-32}$ using nitroalkene or its derivatives with a nitrogen source, namely ethyl[(4-nitrobenzenesulfonyl) oxy] carbamate $\left(\mathrm{N}_{\mathrm{S}} \mathrm{ONHCO} \mathrm{H}_{2} \mathrm{Et}\right) /$ azide, amine or imine (eqn (1)(3) of Scheme 2). Keeping these literature reports in mind, we extended our envisaged aziridination process to the synthesis of 2-nitro-1-tosylaziridine 5 employing the optimized reaction conditions in hand. Thus, a mixture of nitrostyrene 4, PhINTs 2, iodine (10 mol\%) and GO (15 mg) was stirred at room temperature in water and the corresponding 2-nitro-1-tosylaziridine was synthesized in 5-7 h in good to excellent yield (87-91\%) (Table 3). However, nitrostyrenes bearing various types of electron releasing and electron withdrawing groups at the para position were in good agreement with the yield of product 5 (Table 3). Also, the ortho- and meta-substituted phenyl ring afforded approximately the same yield of pure product $\mathbf{5}$. Increasing the mol\% of iodine did not increase the yield. However, decreasing the amount of iodine resulted in substantial suppression of product yield (Table 3, entries 8 and 9). A similar effect was observed when varying the amount of the GO catalyst (Table 3, entries 10 and 11). The ${ }^{1} \mathrm{H}$ NMR spectra of 5a shows two doublets at $\delta 2.28$ and 4.55 for both $\mathrm{CHs}$ in aziridine (5a) with the same coupling constant $(J=9.5 \mathrm{~Hz})$ confirming the formation of nitroaziridine 5 (Fig. S2, ESI $\dagger$ ). Next, the $Z$-stereochemistry of aziridines 5 was assigned on the basis of higher $J$-values $(9.5-9.8 \mathrm{~Hz})$ of $2-\mathrm{H}$ and $3-\mathrm{H}$ than those of $(E)$ aziridines $(6.5-6.6 \mathrm{~Hz})$. This conforms with the earlier observations for aziridines reported in the literature. ${ }^{32-35}$ Furthermore, strong NOEs between $2-\mathrm{H}$ and $3-\mathrm{H}$ in aziridines 5 also confirm that these protons are on the same face of the molecule and thus, prove their $Z$-stereochemistry (Fig. 2). The plausible mechanism for the formation of aziridines 3 and $\mathbf{5}$ is given in Scheme 3. The radical pathway is favoured in the light of the homolytic weakness of the $\mathrm{N}-\mathrm{I}$ bond ${ }^{37}$ and low conversion rate in the dark using the same reaction conditions (Table 1). Initially, PhINTs 2 reacts with $\mathrm{I}_{2}$ in the presence of GO, generating $N, N$-diiodotosylamide $\mathbf{6}$, which is the cornerstone of the present nitrene insertion process. Presumably, homolytic cleavage of the $\mathrm{N}-\mathrm{I}$ bond ${ }^{37}$ of 6 generates the amidyl radical 7 , which is followed by the intramolecular cyclization of $\mathbf{8}$, assisted by the iodine free radical to furnish the target molecules $\mathbf{3}$ and $\mathbf{5}$ with the regeneration of $\mathrm{I}_{2}$, which is to be reused in the catalytic cycle (Scheme 3).

Graphene oxide (GO) is a single hexagonal lattice sheet of $\mathrm{sp}^{2}$ and $\mathrm{sp}^{3}$ hybridized $\mathrm{C}$ atoms. The oxidation of graphite results in

Table 3 Synthesis of 2-nitro-1-tosylaziridine $5^{a}$

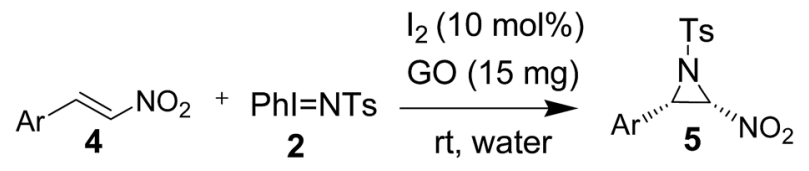

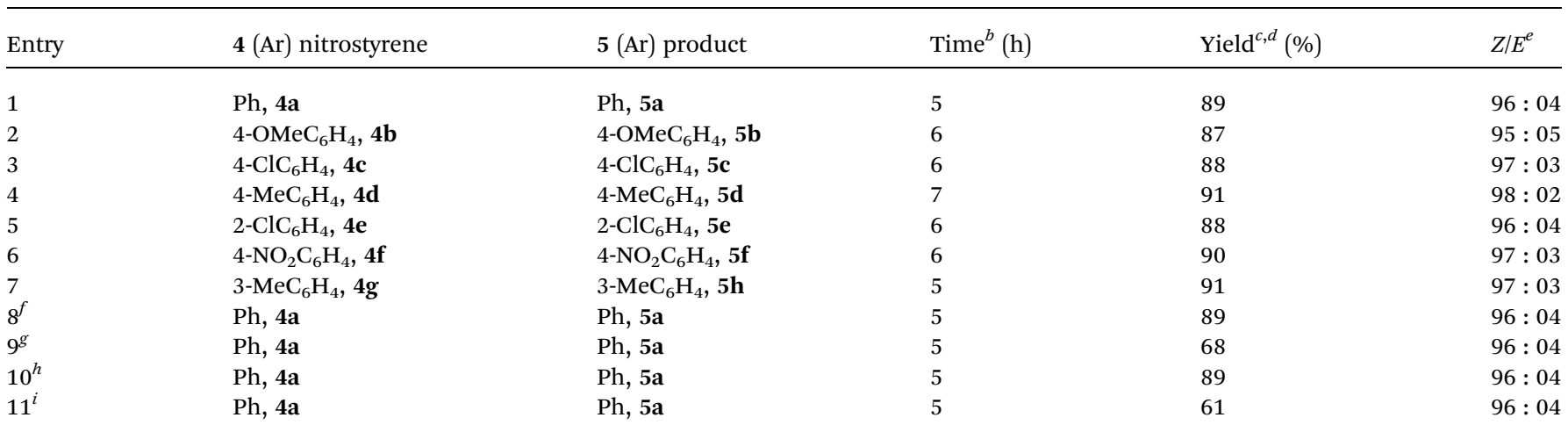

${ }^{a}$ Reaction conditions: a mixture of $4(3.5 \mathrm{mmol}), 2(0.750 \mathrm{mmol}), \mathrm{I}_{2}(10 \mathrm{~mol} \%)$ and $\mathrm{GO}(15 \mathrm{mg})$ dispersed in $5 \mathrm{~mL}$ of water was stirred at room temperature. ${ }^{b}$ The stirring time at room temperature. ${ }^{c}$ Yield of isolated and purified product. ${ }^{d}$ Characterized by spectral $\left(\mathrm{IR},{ }^{1} \mathrm{H}\right.$ NMR, ${ }^{13} \mathrm{C}$ NMR and EIMS) data. ${ }^{e}$ Determined by ${ }^{1} \mathrm{H}$ NMR spectroscopy. ${ }^{f}$ Reaction was performed in 15 mol\% of $\mathrm{I}_{2} \cdot{ }^{g}$ Reaction was performed in 5 mol\% of $\mathrm{I}_{2} \cdot{ }^{h}$ Reaction was performed with $20 \mathrm{mg}$ of GO. ${ }^{i}$ Reaction was performed with $10 \mathrm{mg}$ GO. 


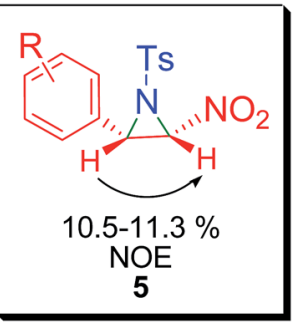

Fig. 2 NOE experiment on nitro-aziridines 5.

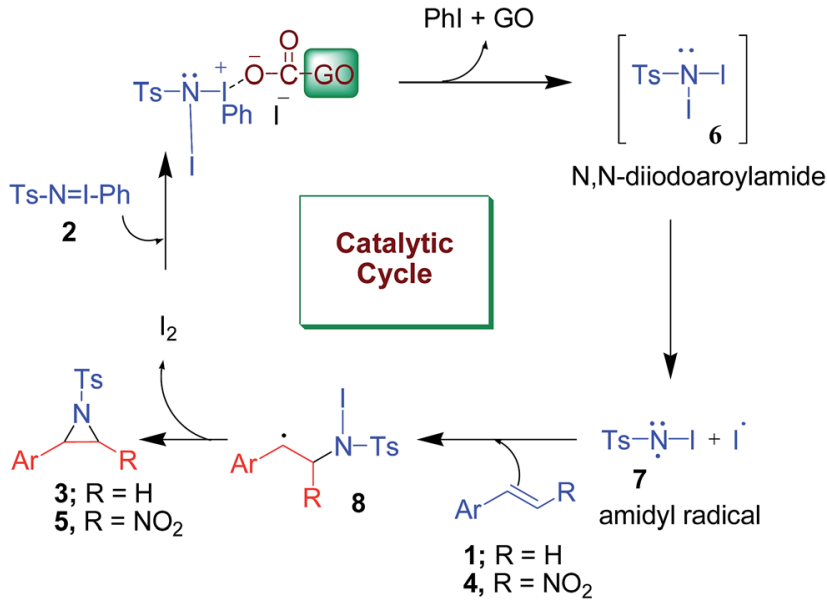

Scheme 3 Plausible mechanism for the formation of tosylaziridines 3 and 5 .

a number of defects or holes on its surface. The presence of numerous - $\mathrm{COOH}$ groups at the edges of flakes as well as at the edges of defect sites may be utilized for its functionalization, which makes GO an efficient catalyst (Fig. 3). ${ }^{36}$ The reusability of GO as a heterogeneous acid catalyst was also examined and it was recovered from the first batch of reactions by centrifugation followed by washing and drying, then it was reused for six subsequent batch reactions. Appreciable conversions were achieved in all recycling experiments carried out at room

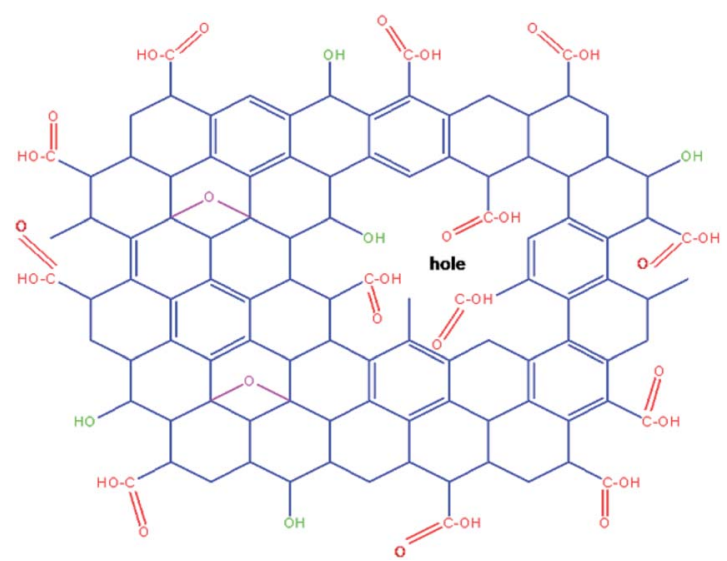

Fig. 3 Various functional groups of the graphene oxide used as a catalyst.

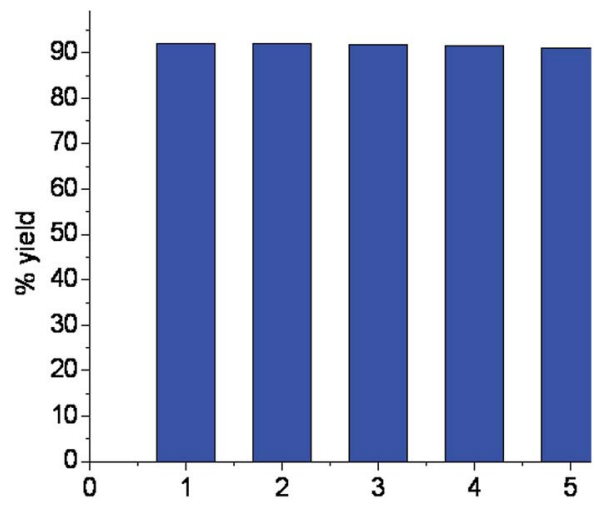

Fig. 4 Reusability experiment of the GO catalyst.
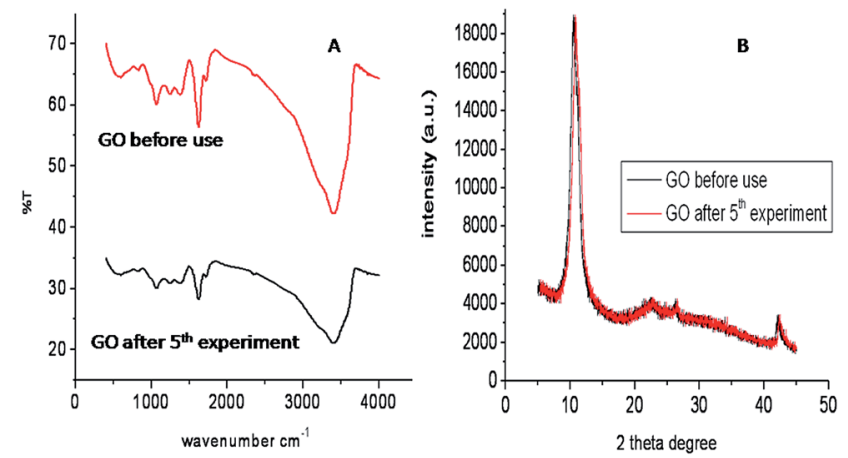

Fig. 5 IR (A) and XRD (B) of GO before and after use in a reusability experiment.

temperature (Fig. 4). Comparison of the FT-IR spectra of GO before and after use confirmed that the catalyst remained the same after the reaction (Fig. 5).

\section{Conclusion}

In summary, we have disclosed an unprecedented and efficient route for the synthesis of tosylaziridines using $\mathrm{PhI}=\mathrm{NTs}$ via nitrene insertion into olefins in the presence of graphene oxide as a catalyst in water. The envisaged green method has several advantages over existing procedures for the synthesis of activated aziridines, viz., higher yields of products, simple operation, and ambient reaction conditions and would be a better practical alternative to cater to the needs of academia as well as industry.

\section{Experimental}

\section{Preparation of graphene oxide}

GO was synthesized from the oxidation of graphite powder under oxidising conditions using the modified Hummers $\operatorname{method}^{29}$ followed by exfoliation in an aqueous solution. Graphite flakes $(1 \mathrm{~g})$ were slowly added to ice-cold concentrated sulfuric acid $(23 \mathrm{~mL})$ then continued stirring was performed, putting the whole mixture in an ice bath along with sodium nitrate $(0.5 \mathrm{~g})$ and then vigorously stirring using a magnetic 
stirrer. After that, potassium permanganate ( $3 \mathrm{~g}$ ) was added to the reaction mixture very slowly, keeping the temperature within $0-5{ }^{\circ} \mathrm{C}$. The mixture was allowed to stir at room temperature for $30 \mathrm{~min}$ forming a thick paste. It was diluted with distilled water $(46 \mathrm{~mL})$ under stirring conditions. The temperature of the solution was raised to about $98{ }^{\circ} \mathrm{C}$ and the mixture was allowed to stir for $4 \mathrm{~h}$ and was then finally cooled down. Then $100 \mathrm{~mL}$ of deionized water was added followed by slow addition of $3 \mathrm{~mL}$ $\mathrm{H}_{2} \mathrm{O}_{2}(30 \%)$. The color of the solution changed from dark brown to yellowish brown. The overall solution was exfoliated under stirring followed by centrifugation at $3000 \mathrm{rpm}$ to collect the solid mass at the bottom. The remaining solid material was then washed with $50 \mathrm{~mL}$ of warm deionised water and $30 \mathrm{~mL}$ of $5 \%$ $\mathrm{HCl}$. Finally, the brown mass was collected and dried at $50{ }^{\circ} \mathrm{C}$ under vacuum to obtain solid graphene oxide. The formation of GO and the presence of various chemical functionalities on the GO nanosheets have been well characterized and analyzed by TEM, XRD, FTIR and UV-Vis spectroscopy.

\section{TEM analysis of graphene oxide}

HR-TEM measurements were performed to determine the morphology of graphene oxide. Bends and wrinkles were observed on the graphene oxide nanosheets at several places (Fig. 6). Graphene oxide nanosheets appear to have a single layer morphology. Well-defined diffraction spots in a selected area electron diffraction (SAED) pattern illustrate that the monolayer graphene oxide formed. However, in the HR-TEM image, the presence of topological features along with an overlapping area of graphene oxide nanosheets reveal that they are highly dispersed in water.

\section{XRD analysis of graphene oxide}

XRD analysis was used to characterize the crystalline nature and phase purity of the as-synthesized graphene oxide. Pure

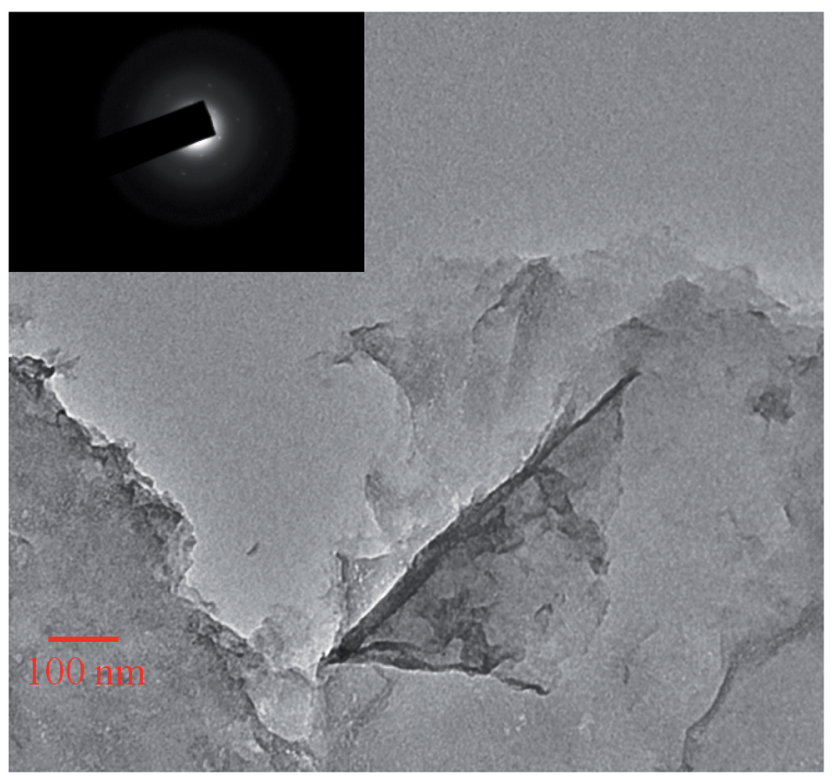

Fig. 6 High resolution TEM image and diffraction pattern (inset) of the graphene oxide nanosheets. graphite has a strong and sharp diffraction peak at $2 \theta=23.62^{\circ}$, which corresponds to the (002) plane of the hexagonal graphite structure with an interlayer spacing of $3.76 \AA$ (Fig. S3, ESI $\dagger$ ). After chemical oxidation and exfoliation into graphene oxide, the $23.62^{\circ}$ peak disappeared and a wide diffraction peak centred at $10.13^{\circ}$ appeared, corresponding to the (002) plane and the interlayer spacing of the material was $8.72 \AA$. An increased interlayer distance between consecutive carbon basal planes is attributed to the intercalation of oxygen functional groups $(-\mathrm{COOH},-\mathrm{OH}$ etc. $)$ and water molecules into the carbon layer structure. XRD shows various defects and functional groups carrying $\mathrm{sp}^{3}$ hybridized carbon atoms, which are introduced during the oxidation process.

\section{FT-IR spectrum of graphene oxide (GO)}

Fig. S4, ESI $\dagger$ shows the FTIR spectrum of GO, which shows a broad peak at $3403.74 \mathrm{~cm}^{-1}$ in the high-frequency area attributed to the stretching mode of the $\mathrm{O}-\mathrm{H}$ bond, revealing the presence of hydroxyl groups in graphene oxide. The band observed at $1725.16 \mathrm{~cm}^{-1}$ was assigned to the carboxyl group. The sharp peak found at $1608.79 \mathrm{~cm}^{-1}$ is a resonance peak that can be assigned to the stretching and bending vibrations of the -OH groups from water molecules adsorbed on graphene oxide. The peak at $1381.42 \mathrm{~cm}^{-1}$ arises from the $\mathrm{C}-\mathrm{OH}$ group. The peak at $1241.65 \mathrm{~cm}^{-1}$ denotes $\mathrm{C}-\mathrm{O}$ (epoxy group) stretching and the $\mathrm{C}-\mathrm{O}$ (alkoxy) stretching vibration bands appear at $1061.08 \mathrm{~cm}^{-1}$. FTIR spectra provide the presence of ample numbers of oxygen functionalities such as hydroxyl, epoxide, carboxylate and carbonyl on graphene oxide.

\section{UV-Vis spectrum of graphene oxide}

The UV-Vis spectrum of graphene oxide is also shown in Fig. S5, ESI. $\dagger$ According to the absorbance spectra, the main spectrum of graphene oxide has a strong absorption peak at $234.32 \mathrm{~nm}$, attributed to the $\pi \rightarrow \pi^{*}$ transition of the $\mathrm{C}-\mathrm{C}$ conjugated aromatic domains and a weak absorption (shoulder) at $306.64 \mathrm{~nm}$ due to the $\mathrm{n} \rightarrow \pi^{*}$ transition of the $\mathrm{C}=\mathrm{O}$ bond.

\section{General method for the synthesis of aziridines 3 and 5}

Styrene $(0.75 \mathrm{mmol})$ was added to a mixture of iodine (10 mol\%), PhINTs $(0.750 \mathrm{mmol})$ and GO $(15 \mathrm{mg})$ in distilled water $(5 \mathrm{~mL})$. The reaction mixture was stirred at room temperature for 10 to $12 \mathrm{~h}$. The reaction progress was recorded periodically and after completion of the reaction (using TLC), the reaction mixture was washed sequentially with diethyl ether $(10 \mathrm{~mL} \times 3)$, brine solution $(10 \mathrm{~mL} \times 3)$ and distilled water $(10$ $\mathrm{mL}$ ) and it was finally dried over potassium carbonate. Evaporation of the solvent on a rotavapor left the crude solid product which was purified by column chromatography on silica gel (ethyl acetate $/ n$-hexane $=1 / 9$ ) to provide the pure products 3 and 5. The products were confirmed by ${ }^{1} \mathrm{H}$ NMR and ${ }^{13} \mathrm{C}$ NMR spectroscopy and all the characterization data match those reported in the literature well. ${ }^{15 h, 32}$ However, the spectroscopic data of representative compounds is given. 3a: IR $(\mathrm{KBr}) \nu_{\max }=$ 3051, 2838, 1603, 1582, $1455 \mathrm{~cm}^{-1} .{ }^{1} \mathrm{H}$ NMR (400 MHz, $\mathrm{CDCl}_{3}$ ): $\delta=2.39\left(\mathrm{~d}, 1 \mathrm{H}, J=4.5 \mathrm{~Hz}, 3-\mathrm{H}_{\mathrm{a}}\right), 2.99\left(\mathrm{~d}, 1 \mathrm{H}, J=7.0 \mathrm{~Hz}, 3-\mathrm{H}_{\mathrm{b}}\right)$, 
$2.43\left(\mathrm{~s}, 3 \mathrm{H}, \mathrm{TsCH}_{3}\right), 3.78$ (dd, $\left.1 \mathrm{H}, J=4.5,7.0 \mathrm{~Hz}, 2-\mathrm{H}\right), 7.87$ (d, $\left.J=8.0 \mathrm{~Hz}, 2 \mathrm{H}_{\text {arom }}\right), 7.21-7.34$ (m, $\left.7 \mathrm{H}_{\text {arom }}\right) \mathrm{ppm} .{ }^{13} \mathrm{C} \mathrm{NMR}(100$ $\left.\mathrm{MHz}, \mathrm{CDCl}_{3}\right): \delta=23.7,34.7,43.8,125.1,126.3,127.5,128.3$, 129.6, 134.1, 136.5, 142.8 ppm. EIMS: $m / z=273\left[\mathrm{M}^{+}\right]$. $\mathrm{C}_{15} \mathrm{H}_{15} \mathrm{NO}_{2} \mathrm{~S}$ : calcd C 65.91, $\mathrm{H} 5.53, \mathrm{~N} \mathrm{5.12}$; found: $\mathrm{C} 65.73, \mathrm{H}$ 5.16, N 5.41. 5a: IR (KBr) $\nu_{\max }=3049,2835,1607,1579,1509$, 1459, $1324 \mathrm{~cm}^{-1} .{ }^{1} \mathrm{H}$ NMR $\left(400 \mathrm{MHz}, \mathrm{CDCl}_{3}\right): \delta=2.12(\mathrm{~s}, 3 \mathrm{H}$, $\left.\mathrm{TsCH}_{3}\right), 2.28(\mathrm{~d}, 1 \mathrm{H}, J=9.5 \mathrm{~Hz}, 3-\mathrm{H}), 4.54(\mathrm{~d}, 1 \mathrm{H}, J=9.5 \mathrm{~Hz}, 2-$ $\mathrm{H}), 7.20-7.41$ (m, $\left.7 \mathrm{H}_{\text {arom }}\right), 7.89$ (d, $\left.J=8.0 \mathrm{~Hz}, 2 \mathrm{H}_{\text {arom }}\right) \mathrm{ppm} .{ }^{13} \mathrm{C}$ NMR (100 MHz, $\left.\mathrm{CDCl}_{3}\right): \delta=23.9,42.9,78.1,125.9,126.6,127.5$, 128.4, 129.3, 131.5, 137.9, 143.9 ppm. EIMS: $m / z=318\left[\mathrm{M}^{+}\right]$. $\mathrm{C}_{15} \mathrm{H}_{14} \mathrm{~N}_{2} \mathrm{O}_{4} \mathrm{~S}$ : calcd C 56.59, H. 4.43, N 8.80; found: C $56.88 . \mathrm{H}$ 4.26, N 8.47.

\section{Conflicts of interest}

There is no conflicts of interest.

\section{Acknowledgements}

We sincerely thank SERB, DST, New Delhi, for the INSPIRE Faculty Research Award (IFA12-CH-61), DST PURSE for publication fees support and AIRF, Jawaharlal Nehru University for providing microanalysis and spectra.

\section{Notes and references}

1 (a) S. Gabriel, Chem. Ber., 1888, 21, 1049; (b) D. Tanner, Angew. Chem., Int. Ed., 1994, 33, 599; (c) Aziridines and Epoxides in Organic Synthesis, ed. A. K. Yudin, Wiley-VCH, Weinheim, Germany, 2006.

2 (a) X. E. Hu, Tetrahedron, 2004, 60, 2701; (b) H. Stamm, J. Prakt. Chem./Chem.-Ztg., 1999, 341, 319; (c) J. B. Sweeney, Chem. Soc. Rev., 2002, 31, 247; (d) M. A. Graham, A. H. Wadsworth, M. Thornton-Pett and C. M. Rayner, Chem. Commun., 2001, 966; (e) R. Maeda, R. Ishibashi, R. Kamaishi, K. Hirotaki, H. Furuno and T. Hanamoto, Org. Lett., 2011, 13, 6240; (f) M. Sayyad, Y. Nanaji and M. K. Ghorai, J. Org. Chem., 2015, 80, 12659; $(g)$ L. Gao, K. Fu and G. Zheng, RSC Adv., 2016, 6, 47192; (h) Z. Jian and J. S. Kalman, Angew. Chem., Int. Ed., 2016, 55, 15026.

3 (a) I. D. G. Watson, L. Yu and A. K. Yudin, Acc. Chem. Res., 2006, 39, 194; (b) S. Dalili, A. Caiazzo and A. K. Yudin, J. Organomet. Chem., 2004, 689, 3604; (c) I. D. G. Watson and A. K. Yudin, J. Org. Chem., 2003, 68, 5160; (d) A. Caiazzo, S. Dalili and A. K. Yudin, Synlett, 2003, 2198; (e) A. Caiazzo, S. Dalili and A. K. Yudin, Org. Lett., 2002, 4, 2597; $(f)$ X. E. Hu, Tetrahedron, 2004, 60, 2701; (g) P. Lu, Tetrahedron, 2010, 66, 2549; $(h)$ V. K. Rai, N. Sharma and A. Kumar, Synlett, 2013, 24, 0097; (i) A. P. Spork and T. J. Donohoe, Org. Biomol. Chem., 2015, 13, 8545; (j) M. Sengoden, R. Irie and T. Punniyamurthy, J. Org. Chem., 2016, 81, 11508.

4 (a) P. Müller, C. Baud and Y. Jacquier, Tetrahedron, 1996, 52, 1543; (b) D. A. Evans, M. M. Faul and M. T. Bilodeau, J. Am. Chem. Soc., 1994, 116, 2742; (c) R. S. Atkinson, Tetrahedron, 1999, 55, 1519.
5 A. Y. Rulev, A. R. Romanov, E. V. Kondrashov, I. A. Ushakov, A. V. Vashchenko, V. M. Muzalevskiy and V. G. Nenajdenko, J. Org. Chem., 2016, 81, 10029.

6 (a) M. Moens, N. De Kimpe and M. D’hooghe, J. Org. Chem., 2014, 79, 5558; (b) S. Nicholas, N. S. Dolan, R. J. Scamp, T. Yang, J. F. Berry and J. M. Schomaker, J. Am. Chem. Soc., 2016, 138, 14658.

7 K. B. Hansen, N. S. Finney and E. N. Jacobsen, Angew. Chem., Int. Ed., 1995, 34, 676.

8 (a) K. Juhl, R. G. Hazell and K. A. Jørgensen, J. Chem. Soc., Perkin Trans. 1, 1999, 2293; (b) R. Pellicciari, L. Amori, N. Kuznetsova, S. Zlotsky and A. Gioiello, Tetrahedron Lett., 2007, 48, 4911.

9 (a) H. Luo, K. Chen, H. Jiang and S. Zhu, Org. Lett., 2016, 18, 5208; (b) B.-N. Lai, J.-F. Qiu, H.-X. Zhang, J. Nie and J.-A. Ma, Org. Lett., 2016, 18, 520.

10 J. E. G. Kemp, in Comprehensive Organic Synthesis, ed. B. M. Trost and I. Fleming, Pergamon, Oxford, 1991, vol. 7, p. 467.

11 A. Padwa and S. S. Murphree, in Progress in Heterocyclic Chemistry, ed. G. W. Gribble and T. L. Gilchrist, Pergamon Elsevier Science, Oxford, 2000, vol. 12, ch. 4.1, p. 57.

12 (a) N. De Kimpe, R. Verheé, L. De Buyck and N. Schamp, Synth. Commun., 1975, 5, 269; (b) N. De Kimpe, L. Moens, R. Verhé, L. De Buyck and N. Schamp, J. Chem. Soc., Chem. Commun., 1982, 19; (c) N. De Kimpe, P. Sulmon, R. Verhé, L. De Buyck and N. Schamp, J. Org. Chem., 1983, 48, 4320; (d) N. De Kimpe, R. Verhé, L. De Buyck and N. Schamp, J. Org. Chem., 1980, 45, 5319.

13 H. M. I. Osborn and J. Sweeney, Tetrahedron: Asymmetry, 1997, 8, 1693.

14 L. Degennaro, P. Trinchera and R. Luisi, Chem. Rev., 2014, 114, 7881.

15 (a) Aziridines and Epoxides in Organic Synthesis, ed. A. K. Yudin, Wiley-VCH, Weinheim, Germany, 2006; (b) S. Minakata, Y. Takeda and K. Kiyokawa, in Methods and Applications of Cycloaddition Reactions in Organic Syntheses, ed. N. Nishiwaki, Wiley-VCH, Weinheim, Germany, ch. 2, ISBN 978-1-118-29988-3; (c) P. Muller and C. Fruit, Chem. Rev., 2003, 103, 2905; (d) G. S. Singh, M. D'hooghe and N. De Kimpe, Chem. Rev., 2007, 107, 2080; (e) T. G. Driver, Org. Biomol. Chem., 2010, 8, 3831; (f) J. W. W. Chang, T. M. U. Ton and P. W. H. Chan, Chem. Rev., 2011, 11, 331; (g) D. M. Jenkins, Synlett, 2012, 1267; (h) K. Kiyokawa, T. Kosaka and S. Minakata, Org. Lett., 2013, 15, 4858.

16 J. M. Mahoney, C. R. Smith and J. N. Johnston, J. Am. Chem. Soc., 2005, 127, 1354.

17 (a) J. U. Jeong, B. Tao, I. Sagasser, H. Henniges and K. B. Sharpless, J. Am. Chem. Soc., 1998, 120, 6844; (b) T. Ando, D. Kano, S. Minakata, I. Ryu and M. Komatsu, Tetrahedron, 1998, 54, 13485; (c) D. Kano, S. Minakata and M. Komatsu, J. Chem. Soc., Perkin Trans. 1, 2001, 3186; (d) S. Minakata, D. Kano, Y. Oderaotoshi and M. Komatsu, Angew. Chem., Int. Ed., 2004, 43, 79; (e) S. Minakata, Y. Murakami, R. Tsuruoka, S. Kitanaka and M. Komatsu, Chem. Commun., 2008, 6363; (f) Y. Murakami, Y. Takeda and S. Minakata, J. Org. Chem., 2011, 76, 6277; (g) I. Saikia, B. Kashyap and P. Phukan, Chem. Commun., 2011, 47, 2967. 
18 (a) T. Siu and A. K. Yudin, J. Am. Chem. Soc., 2002, 124, 530; (b) J. Li, J.-L. Liang, P. W. Hong Chan and C.-M. Che, Tetrahedron Lett., 2004, 45, 2685; (c) J. Li, P. W. H. Chan and C.-M. Che, Org. Lett., 2005, 7, 5801; (d) Y.-M. Shen, M.-X. Zhao, J. Xu and Y. Shi, Angew. Chem., Int. Ed., 2006, 45, 8005; (e) L. B. Krasnova and A. K. Yudin, Org. Lett., 2006, 8, 2011; (f) R. D. Richardson, M. Desaize and T. Wirth, Chem.-Eur. J., 2007, 13, 6745; $(g)$ A. Yoshimura, K. R. Middleton, C. Zhu, V. N. Nemykin and V. V. Zhdankin, Angew. Chem., Int. Ed., 2012, 51, 8059.

19 (a) S. Minakata, Y. Morino, Y. Oderaotoshi and M. Komatsu, Chem. Commun., 2006, 3337; (b) R. Fan, D. Pu, J. Gan and B. Wang, Tetrahedron Lett., 2008, 49, 4925; (c) L. Deiana, G.-L. Zhao, S. Lin, P. Dziedzic, Q. Zhang, H. Leijonmarck and A. Cordova, Adv. Synth. Catal., 2010, 352, 3201.

20 C. Varszegi, M. Ernst, F. van Laar, B. F. Sels, E. Schwab and D. E. De Vos, Angew. Chem., Int. Ed., 2008, 47, 1477.

21 (a) M. M. Dia-Requejo, T. R. Belderrain, M. C. Nicasio, S. Trofimenko and P. J. Perez, J. Am. Chem. Soc., 2003, 125, 12078; (b) M. R. Fructos, S. Trofimenko, M. M. Dia-Requejo and P. J. Perez, J. Am. Chem. Soc., 2006, 128, 11784; (c) A. A. Lamar and K. M. Nicholas, J. Org. Chem., 2010, 75, 7644; (d) L. Maestre, W. M. C. Sameera, M. M. DiaRequejo, F. Maseras and P. J. Perez, J. Am. Chem. Soc., 2013, 135, 1338.

22 H. Kwart and A. A. Kahn, J. Am. Chem. Soc., 1967, 89, 1951.

23 (a) R. Breslow and S. H. Gellman, J. Am. Chem. Soc., 1983, 105, 6728; (b) D. Mansuy, J.-P. Mahy, A. Dureault, G. Bedi and P. Battioni, Chem. Commun., 1984, 1161.

24 (a) D. A. Evans, M. M. Faul and M. T. Bilodeau, J. Am. Chem. Soc., 1994, 116, 2742; (b) P. Dauban, L. Sanière, A. Tarrade and R. H. Dodd, J. Am. Chem. Soc., 2001, 123, 7707.

25 (a) V. K. Rai, P. K. Rai, S. Bajaj and A. Kumar, Green Chem., 2011, 13, 1217; (b) L. D. S. Yadav, S. Singh and V. K. Rai, Green Chem., 2009, 11, 878; (c) L. D. S. Yadav, S. Yadav and V. K. Rai, Green Chem., 2006, 8, 455.

26 (a) F. Verma, P. K. Singh, S. R. Bhardiya, M. Singh, A. Rai and V. K. Rai, New J. Chem., 2017, 41, 4937-4942; (b) A. Rai,
P. K. Singh, P. Shukla and V. K. Rai, Tetrahedron Lett., 2016, 57, 5084; (c) V. K. Rai, G. P. Sahu and A. Rai, Tetrahedron Lett., 2015, 56, 2664; (d) A. K. Singh, R. Chawla, A. Rai and L. D. S. Yadav, Chem. Commun., 2012, 48, 3766; (e) A. Rai, V. K. Rai, A. Singh and L. D. S. Yadav, Eur. J. Org. Chem., 2011, 4302.

27 Y. Yamada, T. Yamamoto and M. Okawara, Chem. Lett., 1975, 361.

28 M. Singh, S. R. Bhardiya, H. Kashyap, F. Verma, V. K. Rai and I. Tiwari, RSC Adv., 2016, 6, 104868-104874.

29 W. S. Hummers and R. E. Offeman, J. Am. Chem. Soc., 1958, 80, 1339.

30 (a) H. Person and A. Foucaud, Sci. Chim., 1975, 281, 325; (b) H. Person and A. Foucaud, Bull. Soc. Chim. Fr., 1976, 7-8, 325; (c) H. Person, F. Tonnard, A. Foucaud and C. Fayat, Tetrahedron Lett., 1973, 14, 2495.

31 J. P. Edasery and N. H. Cromwell, J. Heterocycl. Chem., 1979, 16, 831.

32 L. D. S. Yadav, G. Srivastava and R. Kapoor, Tetrahedron Lett., 2009, 50, 5420.

33 U. K. Nadir and A. Arora, Synth. Commun., 1996, 26, 2355.

34 V. K. Aggarwal, E. Alonso, M. Ferrara and E. S. Spey, J. Org. Chem., 2002, 67, 2335.

35 V. K. Aggarwal and M. Ferrara, Org. Lett., 2002, 2, 4107.

36 (a) K. S. S. K. Muhamad, F. Mohamed, S. Radiman, A. Hamzah, S. Sarmani, K. K. Siong, M. S. Yasir, I. A. Rahman and N. R. A. M. Rosli, AIP conference proceeding, American Institute of Physics, 2016, vol. 1784, p. 040013, DOI: 10.1063/1.4966799; (b) H. Guo, X. Wang, Q. Qian, F. Wang and X. Xia, A green approach to the synthesis of graphene nanosheets, ACS Nano, 2009, 3, 2653-2659; (c) D. R. Dreyer, A. D. Todd and C. W. Bielawski, Chem. Soc. Rev., 2014, 43, 5288; (d) A. M. Dimiev and S. Eigler, A book: fundamental and applications, Wiley publications, 2016, ISBN No-9781-11906940.

37 S. A. Glover, A. Goosen and R. D. S. Venter, S. Afr. J. Chem., 1978, 31, 33. 